\title{
Quantitative and Qualitatively Evaluation of New Technologies in Perspective of Construction Optimization
}

\author{
Hassan Saghi*, Nima Arefizadeh \\ Department of Civil Engineering, Hakim Sabzevari University, Sabzevar, Iran
}

Email address:

h.saghi@hsu.ac.ir (H. Saghi), mohandes.n.arefi@gmail.com (N. Arefizadeh)

To cite this article:

Hassan Saghi, Nima Arefizadeh. Quantitative and Qualitatively Evaluation of New Technologies in Perspective of Construction Optimization. American Journal of Civil Engineering. Special Issue: Research and Practices of Civil Engineering in Developing Countries.

Vol. 3, No. 2-2, 2015, pp. 64-68. doi: 10.11648/j.ajce.s.2015030202.23

\begin{abstract}
Novel research studies to find approaches to reduce the cost and time in technology and materials of construction has resulted in modern technologies including insulating concrete formwork, hebelex blocks materials, roof technology of metal deck, Light Steel Framing and Rebar butt forge welding process. Investigation of the new technologies for construction in terms of the cost and time is the purpose of this paper. At first, these technologies are introduced. Then elements, restrictions and some unique special features of this system are presented. In addition, these technologies are studied in an important regarded for the optimization parameters including the cost and time. This paper provides a quantitative, qualitative and relative comparison between different techniques. Furthermore, new optimized technologies are determined and other new technologies for the investigating factors of optimization are suggested.
\end{abstract}

Keywords: New Technologies, Construction, Construction Optimization, Optimized Technology

\section{Introduction}

Creative searching to find approaches to reduce the cost and time of production of construction materials has led to the introduction of new technologies in construction. New technologies for construction include insulating concrete formwork system, Hebelex block materials, roof technology of metal deck, light steel framing system and Rebar butt forge welding process. The purpose of this paper is to investigate these technologies for construction in term of cost and time. Previous researches presented results in order to introduce and evaluate new technologies for manufactures. According to this research, lack of awareness of the creators from modern methods of construction was reason of not using these technologies in large scale [1].

Also, Hebelex is considered as a good alternative for traditional materials such as brick [2]. Considering the advantages and disadvantages of the light steel framing system, the need to develop manufacturing and machine tools and use of these systems has been known. Furthermore, training of the skilled manpower in the field of installation and working with materials, developing practical regulations and supporting research centers such as universities to cover and eliminate the disadvantages of these systems have been recommended [3]. Therefore, this study aimed to investigate the construction of new technologies from the perspective of the important optimizing factors, i.e., cost and time.

\section{New Technologies for Construction}

A number of new technologies including Insulating concrete formwork system, Hebelex blocks materials, Metal deck roof technology, and Rebar butt forge welding process are investigated, separately and cost and time of each technology are evaluated.

\subsection{Insulating Concrete Formwork System}

Insulating concrete formwork system is a building system including reinforced concrete and polystyrene panels in which the reinforced concrete acts as load-bearing and polystyrene panels act as concrete formwork and thermal and acoustic insulation [1]. As it could be understood from name of this system, after concreting, molds remain. The system includes load-bearing components for walls, ceiling panels and wall separators [1]. Main ingredients in this system are expanded polystyrene that is available with relatively acceptable price. The initial cost of this technology is significant, but for some reasons such as saving transportation cost, speed of 
implementation of the system, and wall thermal insulation at the same time, eventually cost of the product is reduced. Saving transportation cost and increasing implementation speed is achieved due to some reasons such as low weight, easy displacement of parts, and not needing to heavy machinery [5].

Limitation: Due to the use of polystyrene in the system, it is necessary to consider a series of safety cases [6], including that foam polystyrene blocks must be valid in accordance with standards; For example, the block must be fire retarded [6]. This system is used for small residential buildings and villas [6].

\subsection{Hebelex Blocks Materials}

Hebelex is trade name of Aerated Concrete that is invented and introduced for the first time in 1924 by Swedish architect engineer. It is widely used in the United States and Europe [2]. This product (Figure. 1) is now presented with the name of Autoclaved Aerated Concrete (AAC) or Gas concrete [5, 6]. In this production process, bubble and porosity are caused by chemical reaction due to materials such as Aluminum powder [6]. In comparison with other kinds of concrete, these are more suitable in term of thermal insulation [7]. Considering different ways of production it is provided with different brand names, such as SYPOREX, YTON and ARECON [4]. Its ingredients include silicium oxide, cement, calcium oxide and some aluminum powder that are and cooked in $200{ }^{\circ} \mathrm{C}$ and they are produced in sizes $10 * 25 * 15,25 * 25 * 60,60 * 25 * 60$, and $30 * 25 * 60$ cubic centimeters or manufactured with arbitrary and custom made sizes.

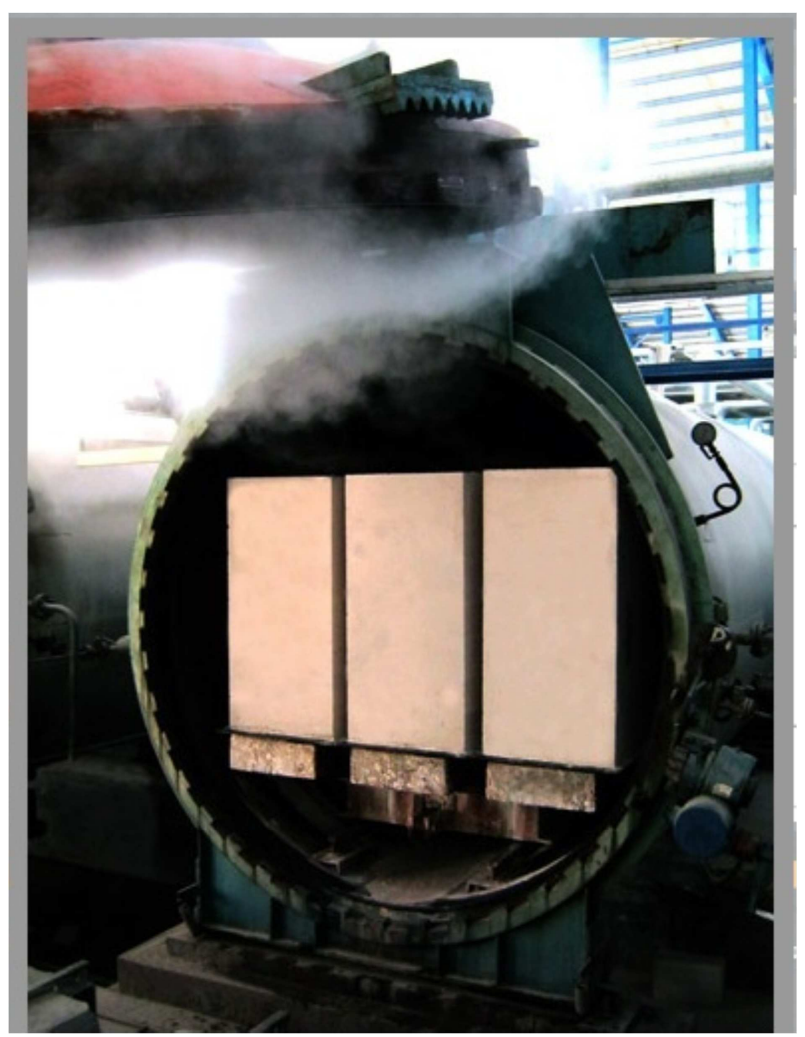

Fig. 1. Production of Hebelex.
Block parts can be made with Portland cement- sand mortar with additional materials, calcium oxide-Portland cement-sand mortar (Batard) and special adhesive. It is recommended that traditional cement and sand mortar (1:6) to be used as leveling mortar under [4]. Since this product is simply cut, wastage of these materials is low. The suitable cutting ability and Navigability accelerate implementation [4]. Cement mortar in the Hebelex wall is 25 percent of the needed materials for producing brick and hence, this product consumes less cement [2]. The relative lightness of this product (Table 1) reduces volume of steel or concrete sections. Not needing to run the liners of Chalk soil on the wall (without intermediary, layer of chalk can be implemented on the Hebelex wall) in case of the proper execution of the work and relative high speed of installation (Table 2) will results in reducing the cost and time of implementation of the wall picking.

Table 1. Comparison of the weight of walls with different materials $\left(\mathrm{kg} / \mathrm{m}^{\wedge} 2\right)$ [4].

\begin{tabular}{lllll}
\hline & \multicolumn{2}{l}{ Type of wall } & \\
\cline { 2 - 5 } Wall Thickness $\left(\mathbf{c m}^{\wedge} \mathbf{2}\right)$ & Brick & $\begin{array}{l}\text { earthenware } \\
\text { block }\end{array}$ & $\begin{array}{l}\text { 3D } \\
\text { Panel }\end{array}$ & Hebelex \\
\hline 10 & 185 & 85 & 110 & 65 \\
20 & 360 & 165 & 130 & 130 \\
\hline
\end{tabular}

Table 2. Comparison of the implementation speed of the various walls by an executive team at a working day $\left(m^{\wedge} 2\right)$ [4].

\begin{tabular}{llll}
\hline \multirow{2}{*}{ Wall Thickness $\left(\mathbf{c m}^{\wedge} \mathbf{2}\right)$} & \multicolumn{2}{l}{ Type of wall } \\
\cline { 2 - 4 } & Brick & earthenware block & Hebelex \\
\hline 10 & 15 & 25 & 45 \\
15 & 10 & & 40 \\
20 & 5 & 20 & 30 \\
\hline
\end{tabular}

Hidden costs of building related to the use of this product in regard to energy (Table 3) and fire resistance, resistance against frost due to the porosity, as well as high durability, and the possibility of recovering the product in the production cycle should be considered. The shortage of the silicium oxide in the future may lead to an increase in the price of this product. Usage limitation of this concrete is determined by its resistance. In this regard, these kinds of concrete are divided into three categories: 2.5, 5, and 7.5 $\mathrm{MPa}$. [8]

Table 3. Compare the Coefficient of Thermal Conductivity $(w /(m * k))$ [4].

\begin{tabular}{lllll}
\hline \multirow{2}{*}{ Wall Thickness(cm^2) } & \multicolumn{4}{l}{ Type of wall } \\
\cline { 2 - 5 } & Brick & $\begin{array}{l}\text { Earthenwa } \\
\text { re block }\end{array}$ & $\begin{array}{l}\text { 3D } \\
\text { Panel }\end{array}$ & Hebelex \\
\hline 20 & 1.81 & 1.52 & 0.62 & 0.13 \\
\hline
\end{tabular}

\subsection{Metal Deck Roof Technology}

In this technique, galvanized sheets with ribbed trapezium sections which are cold-formed are used as the permanent concrete mold and replacement of the major rebar. These galvanized sheets are used up to ceiling span of 4 meters without temporary pillar and to ceiling span of 7 meters with temporary pillar in the midspan (Fig. 2). The materials of the ceiling include metal deck sheets, pegs or stud, rebar, concrete and spacers (rebar to the metal deck) [9]. Restriction 
of using the metal deck plates is in the condition of severe wind blowing (before connection of structural elements). With considering time and cost criteria, we can mention the following points:

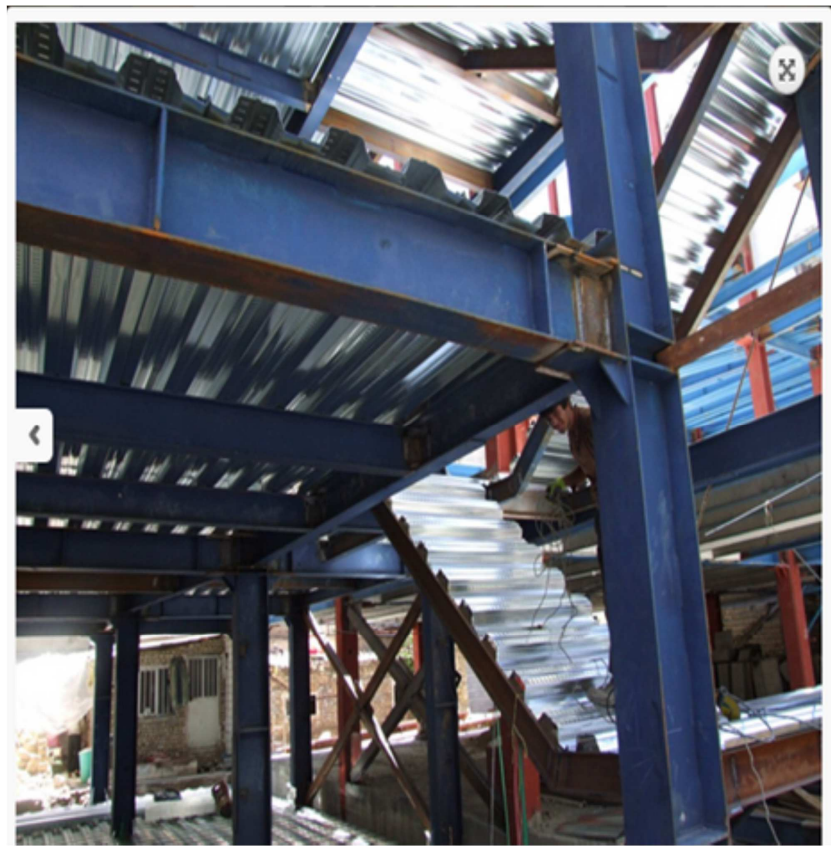

Fig. 2. Galvanized sheets used in temporary pillar in the Midspan.

- Improving the performance and reducing the total cost.

- Reducing the cost of concrete curing with water conservation.

- Relatively reduction of the consumable materials cost (Table 4).

Table 4. Comparison of the materials consumption between metal deck roof and composite per square meter [14].

\begin{tabular}{lll}
\hline Cases & $\begin{array}{l}\text { Composite roof } \\
\text { technology }\end{array}$ & $\begin{array}{l}\text { Metal deck roof } \\
\text { technology }\end{array}$ \\
\hline $\begin{array}{l}\text { Steel } \\
\text { Rebar }\end{array}$ & $\begin{array}{l}\text { An average of } 40 \mathrm{Kg} \\
\text { Concrete with } 350\end{array}$ & $\begin{array}{l}\text { An average of } 28 \mathrm{Kg} \\
8 \phi 30 @(\mathrm{~cm})\end{array}$ \\
$\begin{array}{l}\left.\mathrm{kg} / \mathrm{m}^{\wedge} 3\right) \text { cement content } \\
\text { UNP steel profile }\end{array}$ & $0.1 \mathrm{~m}^{\wedge} 3$ & $0 / 085 \mathrm{~m}^{\wedge} 3$ \\
Plastic & $2 \mathrm{Kg}$ & \\
Welding electrode & $1 \mathrm{~m}^{\wedge} 2$ & \\
Equal angles (L Steel & On average, metal deck consumes $0.5 \mathrm{Kg}$ \\
profile) & On average, metal deck consumes $0.5 \mathrm{Kg}$ \\
Foundation rebar & $\begin{array}{l}\text { lesser than composite. } \\
\text { On average, metal deck is } 2 \mathrm{Kg} \text { lighter than }\end{array}$ \\
Shear wall rebar & $\begin{array}{l}\text { On average, metal deck is } 1.2 \mathrm{Kg} \text { lighter than } \\
\text { composite. }\end{array}$ \\
\hline
\end{tabular}

In order to improve the performance and reduce the total cost, the following methods can be used:

1. The ability to run several roof formatting simultaneously (albeit, in the case of the suitable temporary side bracing) or the ability to install a quick platform in all levels [10]

2. The ability to install elevator on the roof (assuming proper bracing).
3. The ability of faster installation of the stairways [10] (Fig. 3).

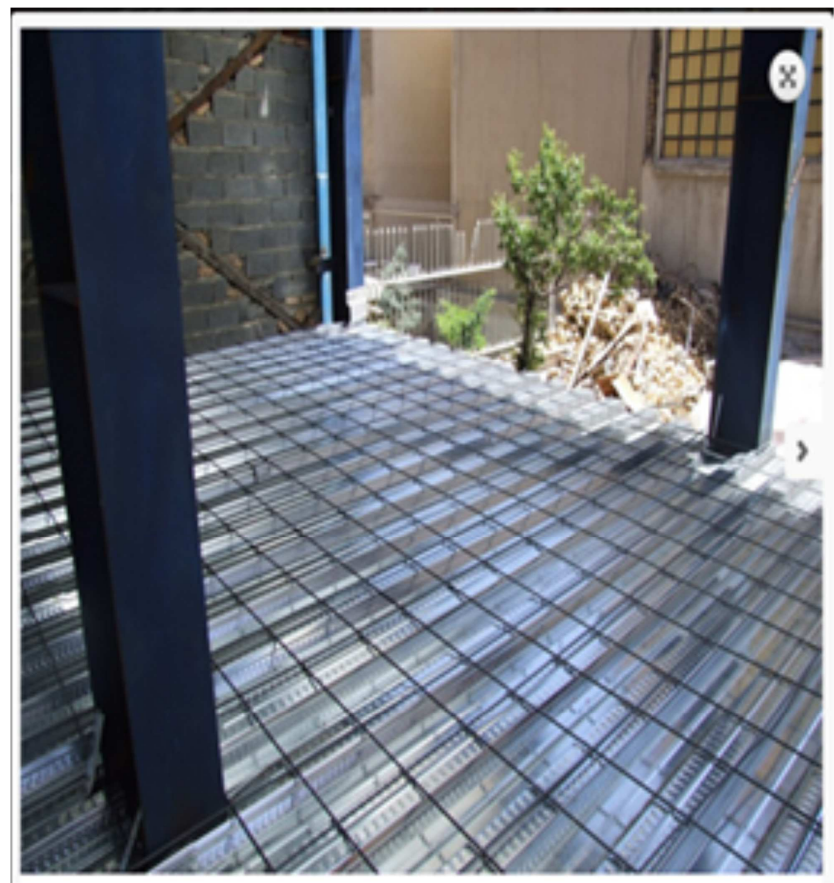

Fig. 3. The ability of faster installation of the stairways [13].

\subsection{Lightweight Steel Frame}

Lightweight steel (LFS) frame (Fig. 4) is made from cold rolled steel sections [11]. Using of this system is one of the suitable ways to build additional floor in the structure. The main components include cold-formed galvanized steel profile that are shaped in $\mathrm{Z}, \mathrm{C}$ and $\mathrm{U}$ sections. These components are used horizontally or vertically and at specific intervals and also self-dilling screws or nuts and bolts are employed for connecting them. [11]

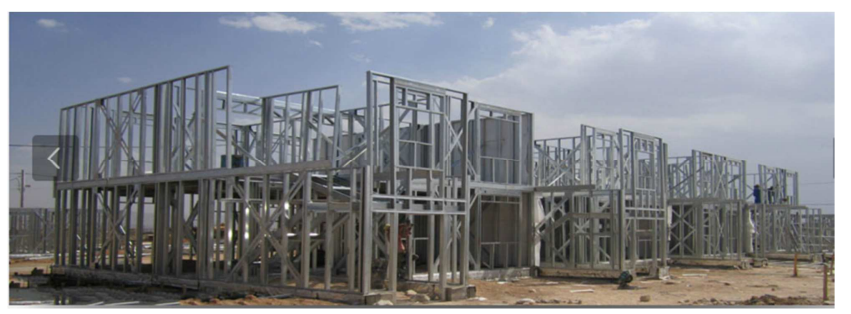

Fig. 4. Light weight steel.

Peripheral components include gypsum board or cement board or polystyrene foam [3]. This type of roof is usually sloped which is made of metal trusses. The trusses are made of cold-rolled profiles. Also, other parts of the building are implemented by using cold-rolled steel and with a variety of boards (gypsum, cement, wood) [12]. Restriction of the usage of the LSF in the windy areas is that the number of stages is limited to 5, and maximum to 8 in some special cases [15]. By studding the cost and time criteria, it can be concluded that using this technique the speed is increased and cost of the materials is reduced (Table 5). 
Table 5. Comparison of the features of traditional buildings and LSF system.The average specifications of Buildings 2, 3 and 5 floors [3].

\begin{tabular}{lllll}
\hline $\begin{array}{l}\text { The row } \\
\text { number }\end{array}$ & Quantity & Concrete & Steel & LSF \\
\hline 1 & $\begin{array}{l}\text { Steel weight } \\
\left(\mathrm{kg} / \mathrm{m}^{\wedge} 2\right)\end{array}$ & 37.2 & 62.5 & 28.6 \\
2 & $\begin{array}{l}\text { Concrete weight } \\
\left(\mathrm{kg} / \mathrm{m}^{\wedge} 2\right)\end{array}$ & 1197 & 529 & 245 \\
3 & $\begin{array}{l}\text { Skeleton weight } \\
\text { (ton) }\end{array}$ & 213 & 19.4 & 7.1 \\
4 & Total weight (ton) & 489 & 340.9 & 160.7 \\
5 & Cutting the & 57 & 39.2 and 43.9 & 28.8 \\
6 & earthquake (ton) & 2.1 & $6.5,3.15$ & 1.2 \\
7 & Displacement $(\mathrm{cm})$ & 80 & 70 & 25 \\
\hline
\end{tabular}

\subsection{Head to Head Forging Welding}

This technology was invented in 1952, having the aim to use in the rail transportation industry. Over time, it is expanded into the construction industry due to its advantages (Fig. 5) [16].

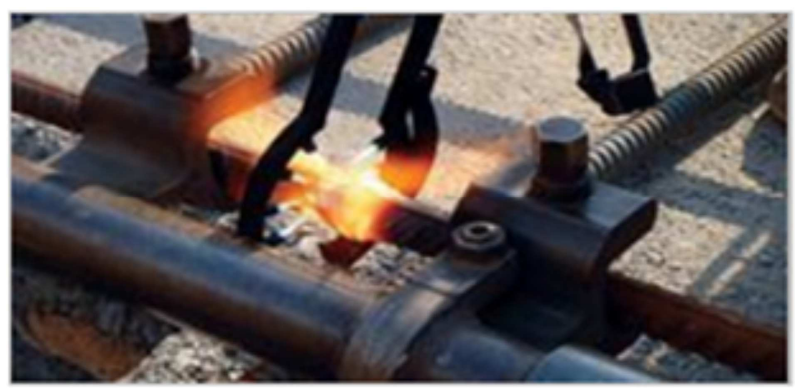

Fig. 5. Head to head forging welding.

In this way, speeding up the construction could be achievable, by taking advantage of the followings [17]:

1. Decreasing consumed rebar ratio, with respect to the rebar diameter and its specified brokerage.

2. Waste rebar could be appropriately connected, to be re-used in construction process.

3. Reducing latent cost by increasing the resistance and persistence of the structure [17].

4. Increasing time and cost of operating mistakes, such as: when length of an armature root being short.

It is noteworthy to mention that reducing final cost are effected by time and cost, will be done with regards to above mentioned methods.

To complement the aforementioned method, the following points should be considered:

1. For instance, decreasing 25-35\% of vertical consumed rebar's taking place is sheer walls with respect to the following assumption:

Firstly, similar vertical reinforcement all over the height of the sheer wall from the foundation elevation up to the highest floor, is done. Moreover, vertical rainforest are typically connecting on each floor.

2. These advantages will be provided due to removing the armature patch, it is noteworthy, according workshop executive formula this length is 60 times longer than nominal diameter of the larger rebar, however, the maximum nominal diameter is residential constructions are limited to 28 millimeter.

3. According to [16] consultant Company reports using forging methods in case of rebar with nominal diameter less than 18 has no economic justification[16]. Regarding aforementioned points, an interval for decreasing vertical consumed rebar, will be predicted. For instance, suppose a building structure with height of $324 \mathrm{~cm}$ for sheer walls, the mentioned interval will be calculated by the following formula (Equation 1):

$$
\begin{aligned}
& (18 * 60 / 10) /[(18 * 60 / 10)+324] \leq \text { interval } \\
& \leq(28 * 60 / 10) /[(28 * 60 / 10)+324]
\end{aligned}
$$

$$
0 / 25 \leq \text { interval } \leq 0 / 35
$$

This formula is based on the proportion of armature patch length to the brokerage length.

In this method nominal diameter is limited to lower band 18 and upper bond 28. In addition, the coefficient of 60 is related calculating patch length of the rebar. Additionally, number of 324 is the height of the sheer walls for each story.

Clearly, this formula is expressed in SI. Not using this method, the waste rebar must be sold cheaper than its buying costs. This benefit will be achieved providing better condition for vibration due to the decrease of weight of extra rebar in place of joints rather than mechanical patch method. If one does not use the proposed method for solving the problem of length of the rebar root being short, another method have to be used. Such as implanting bolts which are relatively more expensive and wasting time.

\section{Discussion, Conclusion and Recommendations}

This article presented a quantitative and qualitatively evaluation of new technologies in perspective of construction optimization using relative parameters analysis method in terms of the cost and time. It seems that the presented new technologies provide the possibility to a quicker return of the investment with increasing the speed of construction, and thus reducing the time. Also, they will eventually reduce cost of building with reducing amount of consumed materials. As a result, these new technologies are innovative technologies to optimize manufacturing.

It is suggested to investigate optimization criteria of other new technologies such as dry wall technology (Dry Wall), polymeric or sprayed plaster, and Concrete-Filled Steel Tubular Columns (CFT).

\section{References}

[1] M. Mansouri and F. Hatami Bargh, " Investigating Insulating concrete formwork (ICF)," First National Congress on Construction Engineering and Projects Assessment, Gorgan, Iran, 2014. 
[2] R. Zare'ian, A. R. Raeisi Vanani, M. R. Ghasemian, "performance review and comparison Heblex as an alternative to the brick", $2^{\text {nd }}$ Conference National of new findings in Civil Engineering, Islamic Azad University of Najaf Abad, 2012.

[3] A. Rahman, "The advantages and disadvantages of the light steel frame", National Conference on Structure, Road, and Architecture, Chalus Azad University, 2011.

[4] www.hebelexbirjand.com.

[5] M. Golabchi and H. Mazaherian, "New Architectural Technologies," Tehran University, Tehran, 1388.

[6] B. Mohammadkari, et al, "Insulating Concrete Formwork system (ICF), Collection of research reports, Review and evaluation of the proposed system in residential buildings, Mass housing projects, Building and housing research center of Iran, Tehran, 1387; (G-493): 52.

[7] M. Monzavi, M. Kermani, H. sobhani, "Evaluation and requirements for lightweight concrete in industrialization, Construction industry of new technologies journal, 1390; (2): 59 .

[8] Iran's National Building Regulations Office, "Section 5, National Building Regulations- Building materials and products," 4th, Tehran, Iran's development, 1393; 62.
[9] www.bornaista.com.

[10] H. Hatefi, "Comparison of the roof (composed of steel concrete) with common combined ceilings" Construction industry of new technologies journal, 1390; (1): 13.

[11] www.ista-lsf.ir.

[12] B. Mohammadkari, et al, "Lightweight Steel Frame (LSF)," Collection of research reports, Review and evaluation of the proposed system in residential buildings, mass housing projects, building and housing research center of Iran, Tehran, 1387; (G-488): 3,65.

[13] www.padabgostar.comR9.

[14] www.arshdamoun.com.

[15] A. R. Raeisi Vanani, R. Zare'ian, E. Rezaei, "Studding the light steel frame structures (LSF), causes and mechanisms of its development in developing countries", $2^{\text {nd }}$ National Conference of new findings in Civil Engineering, Islamic Azad University of Najaf Abad, 2012.

[16] http://forjing.sts-weld.com.

[17] www.parsasaze.com. 